\title{
Enhancement in Desalination Performance of Battery Electrodes via Improved Mass Transport using a Multi-Channel Flow System
}

Jiho Lee,,${ }^{a, 1}$ Jaehan Lee, ${ }^{b, 1}$ Jaewuk Ahn, ${ }^{a}$ Kyusik Jo, ${ }^{a}$ Sung Pil Hong, ${ }^{a}$ Choonsoo Kim, ${ }^{c}$ Changha Lee, ${ }^{a}$ Jeyong Yoon ${ }^{a, d *}$

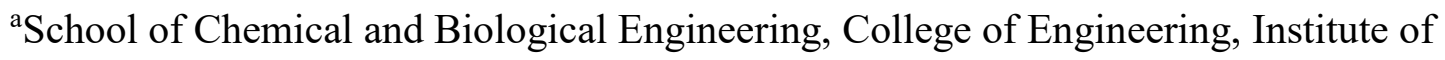
Chemical Process, Seoul National University (SNU), 1 Gwanak-ro, Gwanak-gu, Seoul 08826, Republic of Korea

${ }^{\mathrm{b}}$ Department of Biological and Chemical Engineering, College of Science and Technology, Hongik University, 2639 Sejong-ro, Sejong-si 30016, Republic of Korea

${ }^{\mathrm{c}}$ Department of Environmental Engineering and Institute of Energy/Environment Convergence Technologies, Kongju National University, 1223-23, Cheonan-daero, Cheonansi 31080, Republic of Korea

${ }^{\mathrm{d}}$ Korea Environment Institute, 370 Sicheong-daero, Sejong-si 30147, Republic of Korea

*Jeyong Yoon (corresponding author)

E-mail: jeyong@snu.ac.kr; Phone: +82-2-880-8927; Fax: +82-2-876-8911

${ }^{1}$ These authors contributed equally to this work.

Keywords: Water treatment, Multi-channel flow system, Electrochemical ion separation, Desalination battery, Prussian blue analogue 
(a)

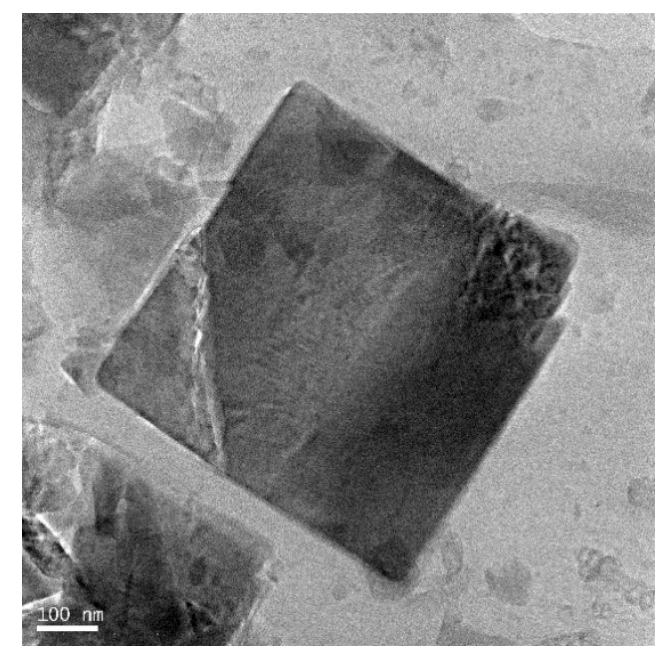

(b)

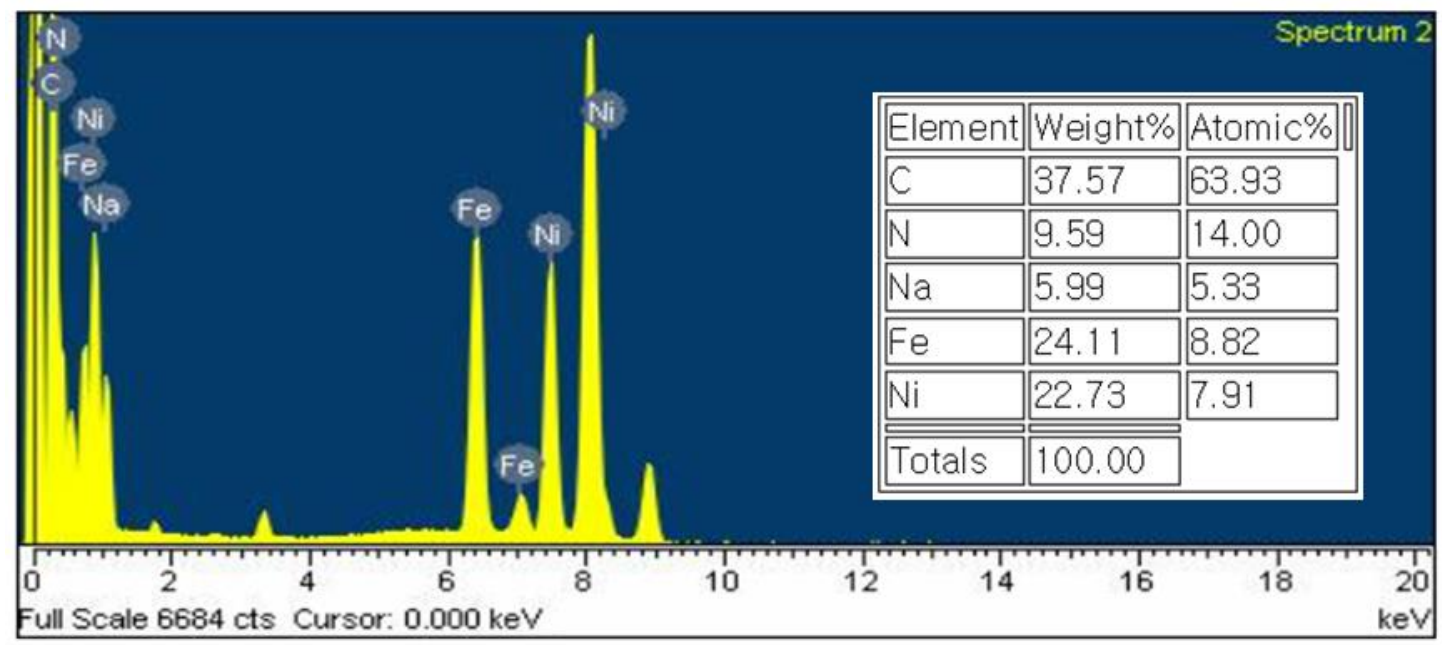

Figure S1. (a) High-resolution transmission electron microscope (HRTEM) image of NiHCF and (b) energy-dispersive X-ray spectroscopy (EDS) intensity peaks and weight composition of the elements (C, N, Na, Fe, and $\mathrm{Ni})$. 
(a)

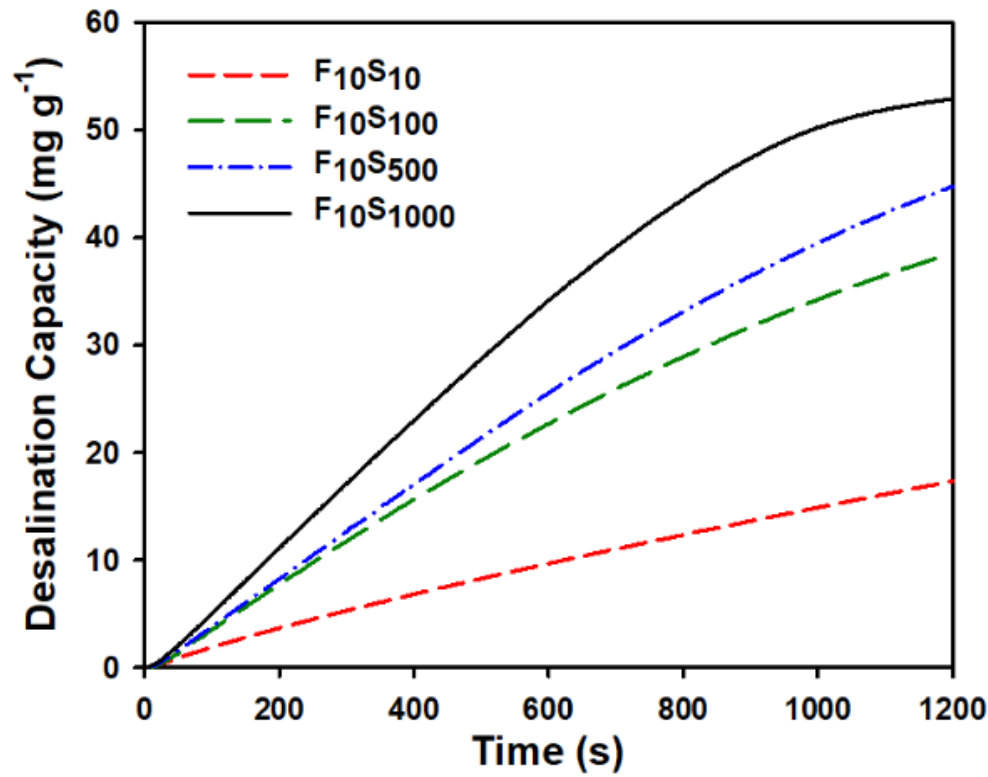

(b)

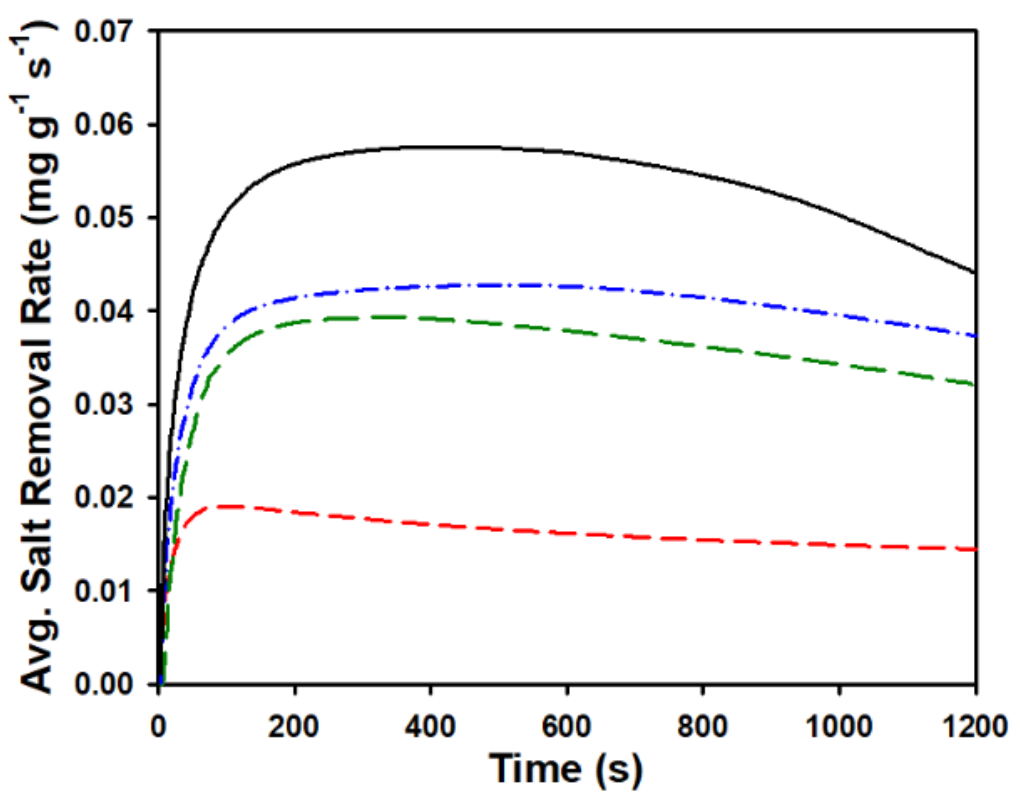

Figure S2 Changes of (a) desalination capacity and (b) average salt removal rate of multichannel desalination battery (MC-DB) operated in various side channel concentration (10 $1000 \mathrm{mM} \mathrm{NaCl}$ ) with respect to time. 


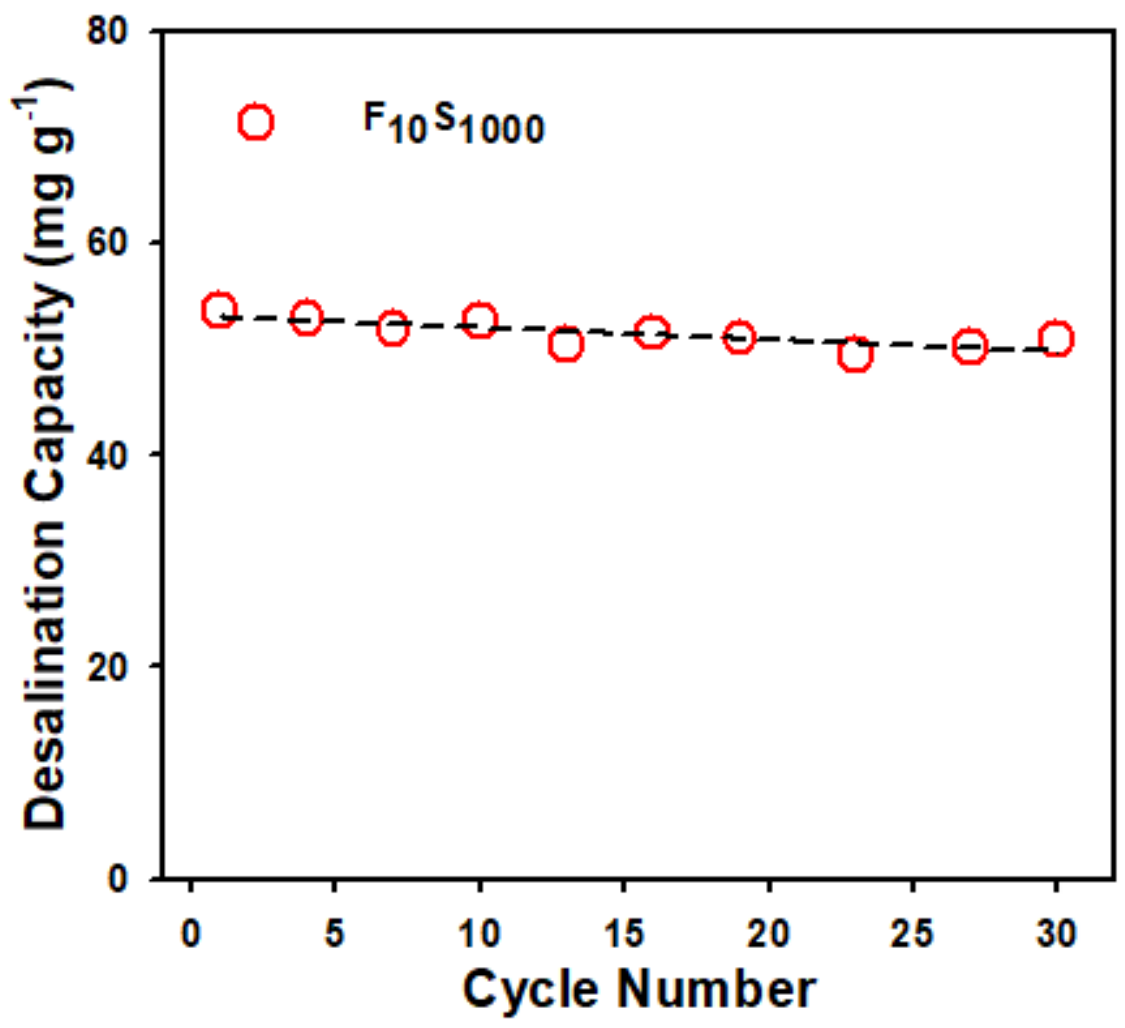

Figure S3 Desalination capacity change of multichannel desalination battery (MC-DB) system with $10 \mathrm{mM}$ and $1000 \mathrm{mM} \mathrm{NaCl}$ in the middle feed and side channels, respectively $\left(\mathrm{F}_{10} \mathrm{~S}_{1000}\right)$, for 30 cycles. 


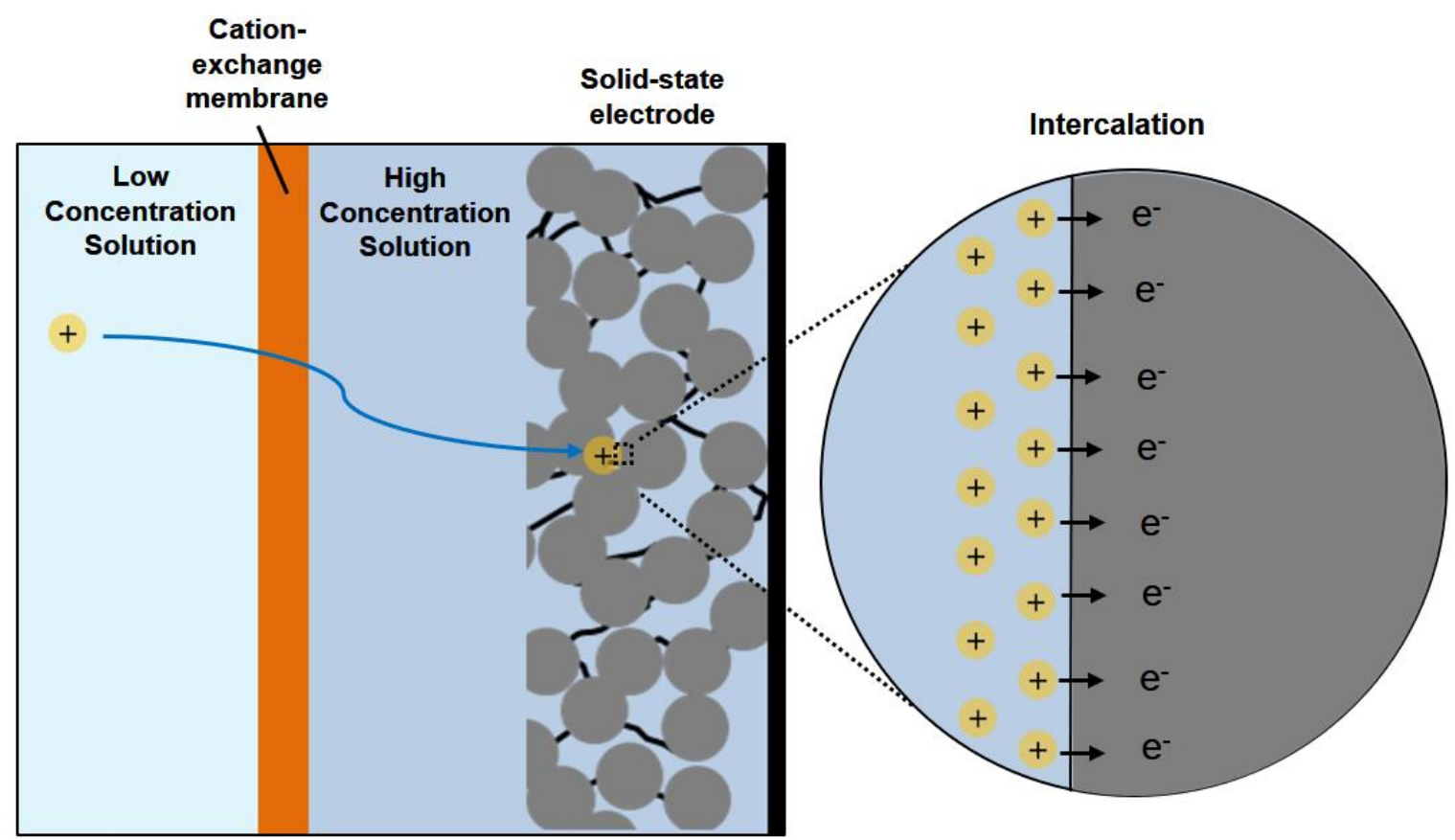

Figure S4 Schematic of transport regions of cation in the multi-channel desalination battery (MC-DB) during the desalination (intercalation) step. Cation transfer across the four main regions: low concentration solution, cation-exchange membrane, high concentration solution, and the active materials in the solid-state electrodes (gray). 
(a)

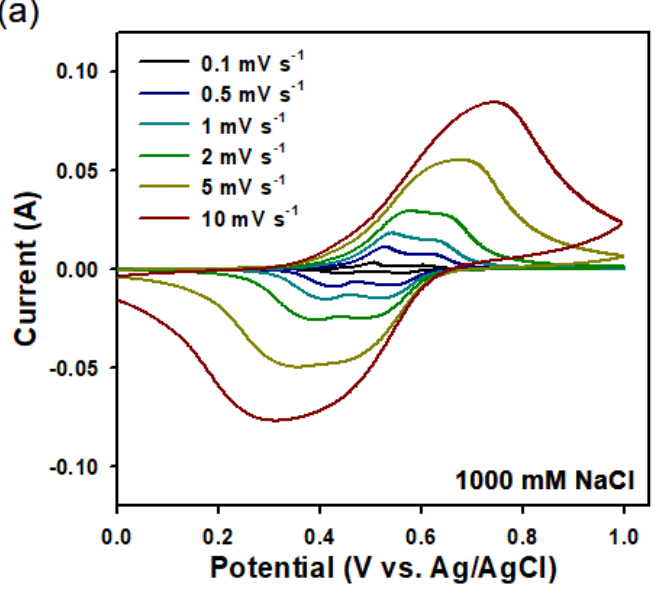

(c)

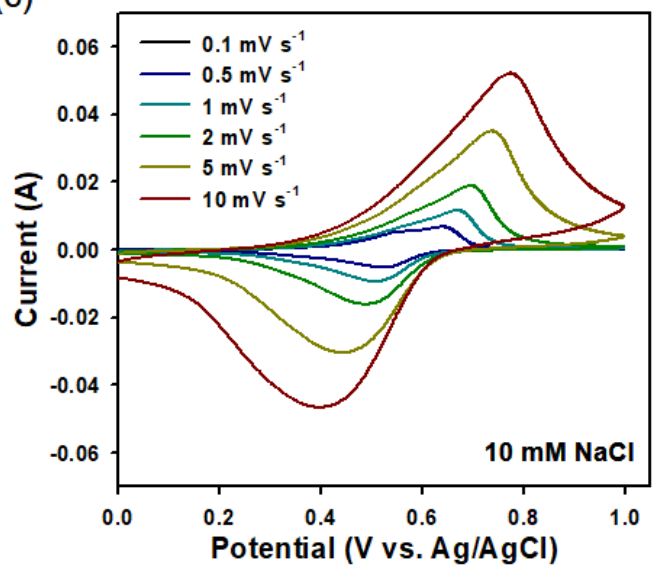

(b)

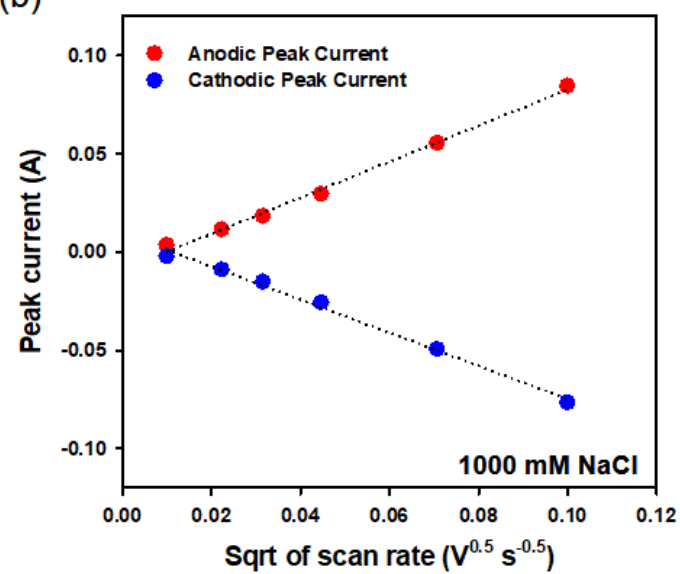

(d)

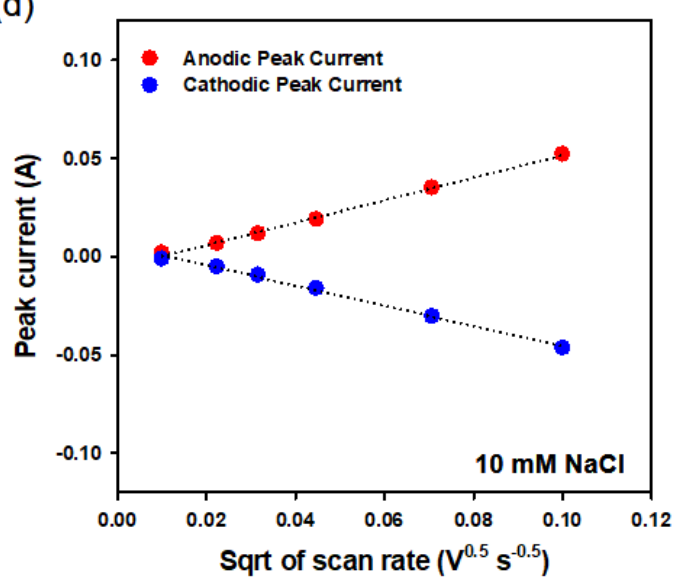

Figure S5 The cyclic voltammogram of nickel hexacyanoferrate (NiHCF) and corresponding peak current vs. square root of scan rate curves measured in (a), (b) $1000 \mathrm{mM}$ and (c), (d) 10 $\mathrm{mM} \mathrm{NaCl}$. The gradients of the lines of best fit during the anodic peak currents are 0.917 and $0.571 \mathrm{~A} \mathrm{~V}^{-0.5} \mathrm{~s}^{0.5}$, respectively, for $1000 \mathrm{mM}$ and $10 \mathrm{mM} \mathrm{NaCl}$.

Randles-Sevcik equation: $\quad i_{\text {peak }}=0.4463 \times \sqrt{\frac{n^{a} F^{a}}{R T}} \times \sqrt{D} \times C_{0} \times A \times \sqrt{V_{\text {rate }}}$ where $n$ is the number of electrons involved in the reaction, $D$ is the average diffusion coefficient, $C_{0}$ is the concentration of active sites, $V_{\text {rate }}$ is the scan rate, $F$ is the Faraday constant $\left(96485 \mathrm{C} \mathrm{mol}^{-1}\right), A$ is the geometric area of the electrode, $R$ is gas constant and $T$ is the temperature. $C_{0}$ can be estimated from the specific capacity and density of the material 


\section{Supplementary Note 1:}

\section{Electrochemical Impedance Spectroscopy (EIS) characterization}

The assembled MC-DB system was further characterized using EIS to observe changes in the resistance of the system as side channel concentration varied. EIS was conducted in twoelectrode system using VersaStat 3 (Ametek) potentiostat. $10 \mathrm{mM} \mathrm{NaCl}$ was fed into the middle feed channel and $\mathrm{NaCl}$ concentration varying from $10-1000 \mathrm{mM}$ was supplied in the side channels in flow rate of $5 \mathrm{ml} \mathrm{min}{ }^{-1}$. The frequency ranging from $100 \mathrm{kHz}$ to $10 \mathrm{mHz}$ were scanned with amplitude of $5 \mathrm{mV}$.

The Nyquist plot shown in Figure S6(a) indicates how the resistance of MC-DB system changes with the side channel concentration. The obtained results were simulated using equivalent circuit as provided in the inset of the Figure $\mathbf{S 6}$ (a). The circuit model was composed of three resistances (series resistance $\left(\mathrm{R}_{\mathrm{S}}\right)$, high frequency region resistance $\left(\mathrm{R}_{\mathrm{h}}\right)$, and charge transfer resistance $\left.\left(\mathrm{R}_{\mathrm{ct}}\right)\right)$, two constant phase elements, and the Warburg impedance. $R_{\mathrm{s}}$ included resistances from the solution and ion-exchange membranes. Although it is difficult to distinguish all the resistance components in the high frequency region, there have been reports indicating that the interfacial contact between the current collector and the carbon paste/binder system can act as a notable resistance, which is denoted as $R_{h}{ }^{1,2} R_{c t}$ referred to charge transfer resistance occurring at the electrodes. As can be observed from Figure S6(b), all three resistances were reduced significantly as side channel concentration increased from 10 to $1000 \mathrm{mM}$. This reduction in the total internal resistance explains the enhancement of desalination performance of the MC-DB system when highly concentrated solutions were supplied to the side channel, which provided a favorable condition for the battery electrodes to undergo reversible Faradaic reaction. 

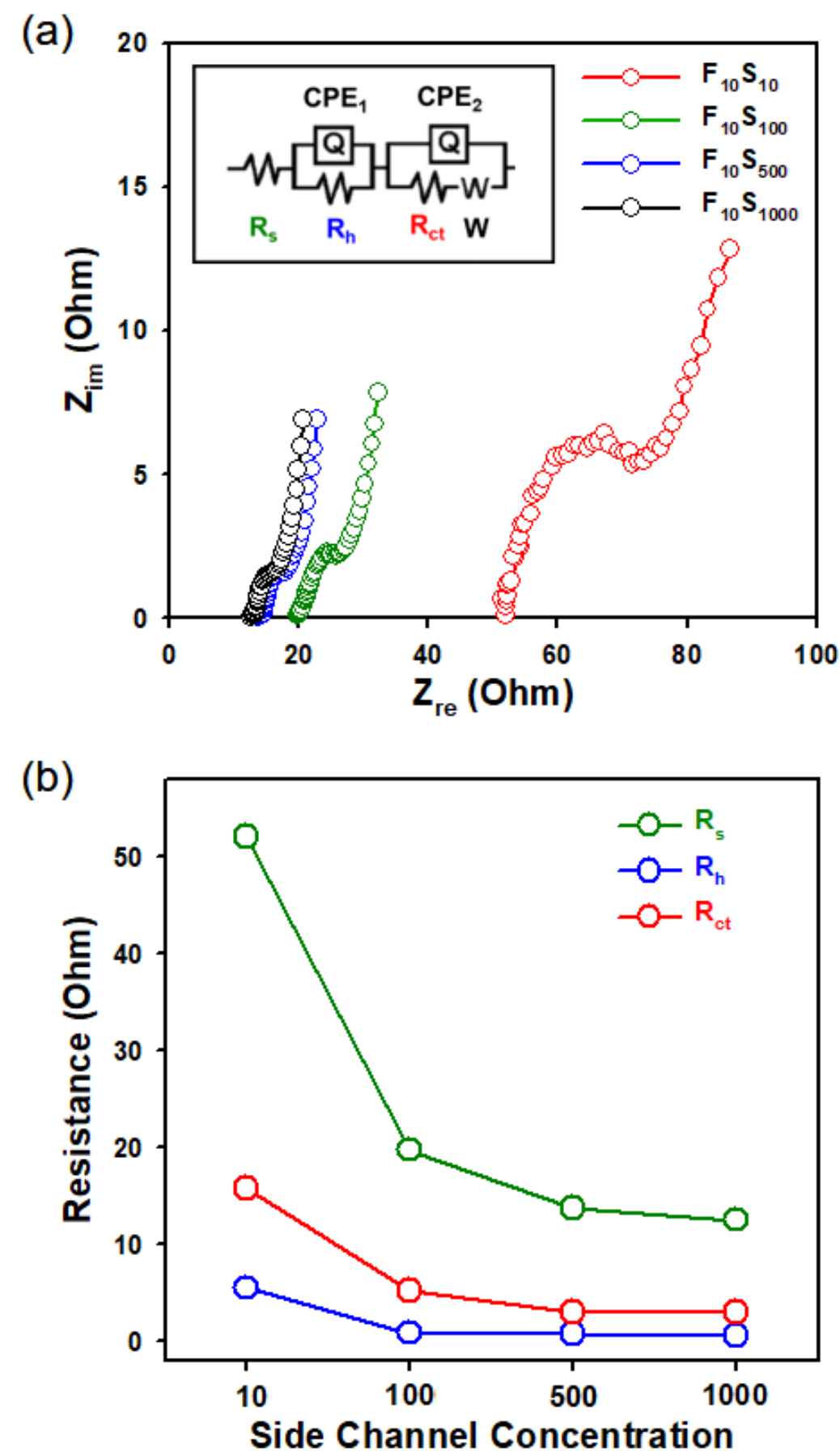

Figure S6 (a) Nyquist plot of MC-DB systems with $10 \mathrm{mM}$ middle feed stream and various side channel concentration $(10-1000 \mathrm{mM})$. The equivalent circuit model was provided in the inset. (b) Changes in the three resistance $\left(\mathrm{R}_{\mathrm{s}}\right.$ (membrane, electrolyte, etc), $\mathrm{R}_{\mathrm{h}}$ (carbon additive/binder), $\mathrm{R}_{\mathrm{ct}}$ (charge transfer)) with respect to the side channel concentration. 


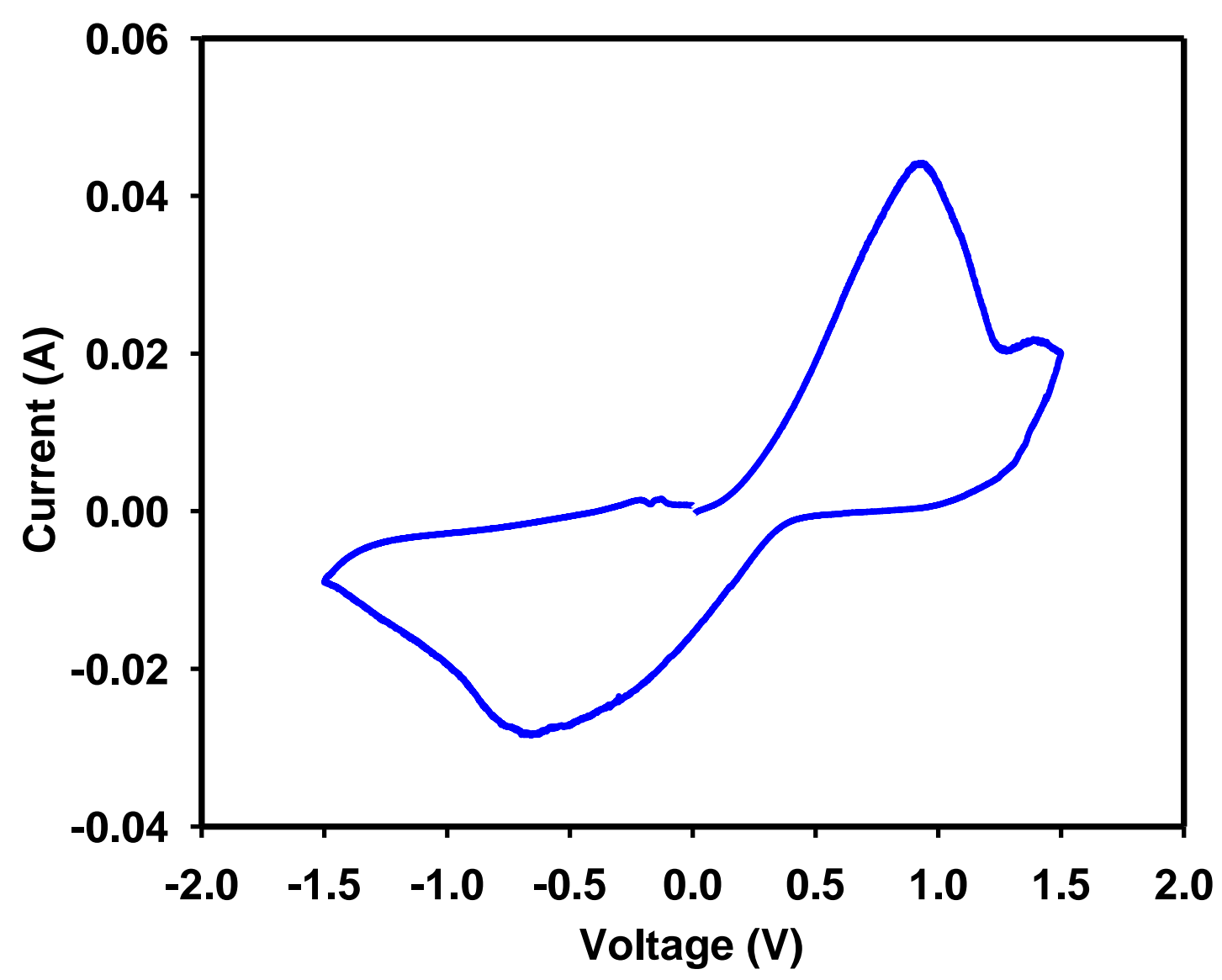

Figure S7 Cyclic voltammogram of the multi-channel desalination battery (MC-DB) system composed of NiHCF and $\mathrm{Ag}$ electrodes. $1000 \mathrm{mM} \mathrm{NaCl}$ was fed to the side channels whereas $10 \mathrm{mM} \mathrm{NaCl}$ was supplied to the middle feed channel $\left(\mathrm{F}_{10} \mathrm{~S}_{1000}\right)$. Voltage window of -1.5 to $1.5 \mathrm{~V}$ was scanned with a rate of $2 \mathrm{mV} \mathrm{s}^{-1}$. 


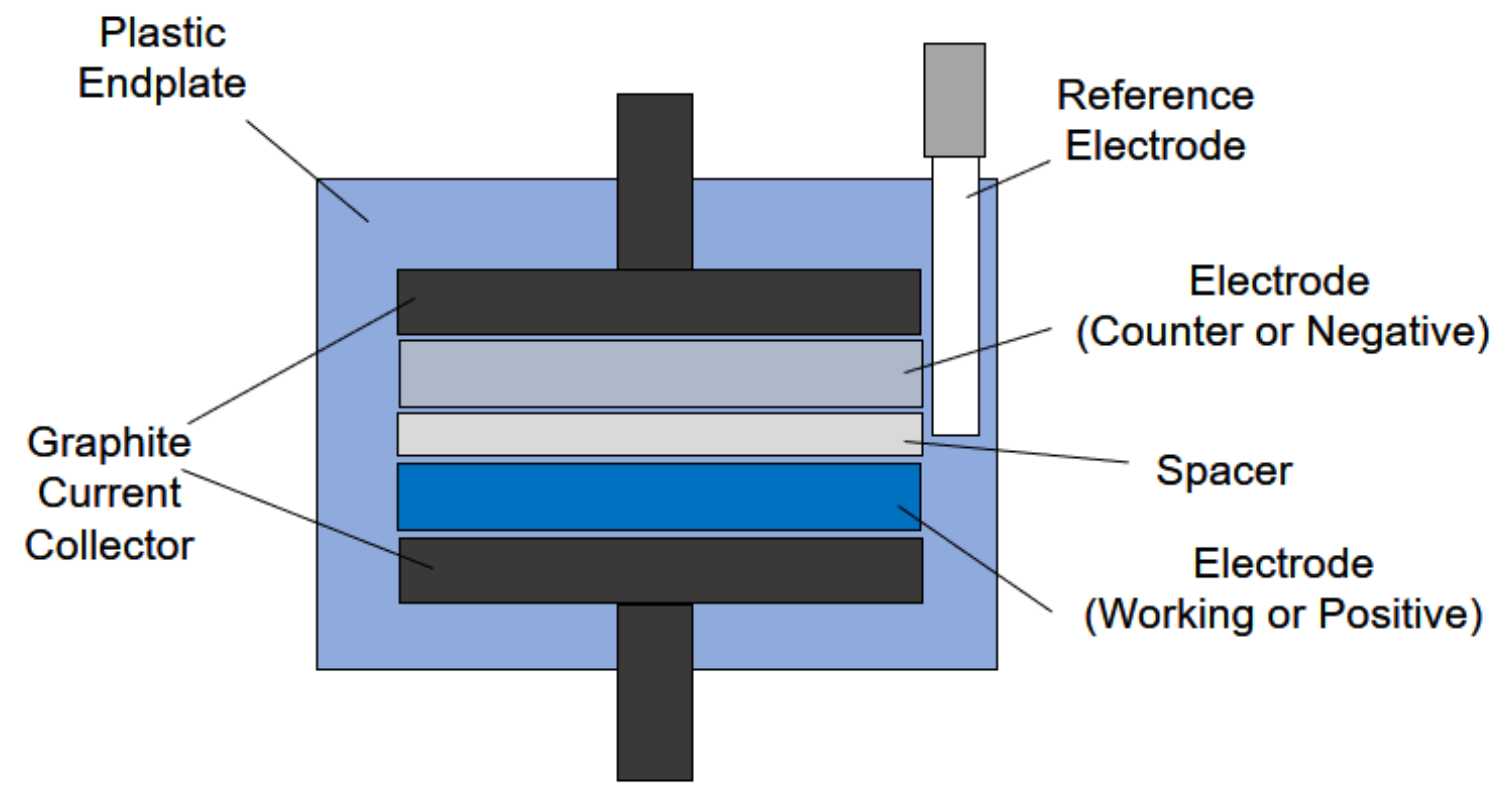

Figure S8 Illustration of custom-built electrochemical characterization cell. 


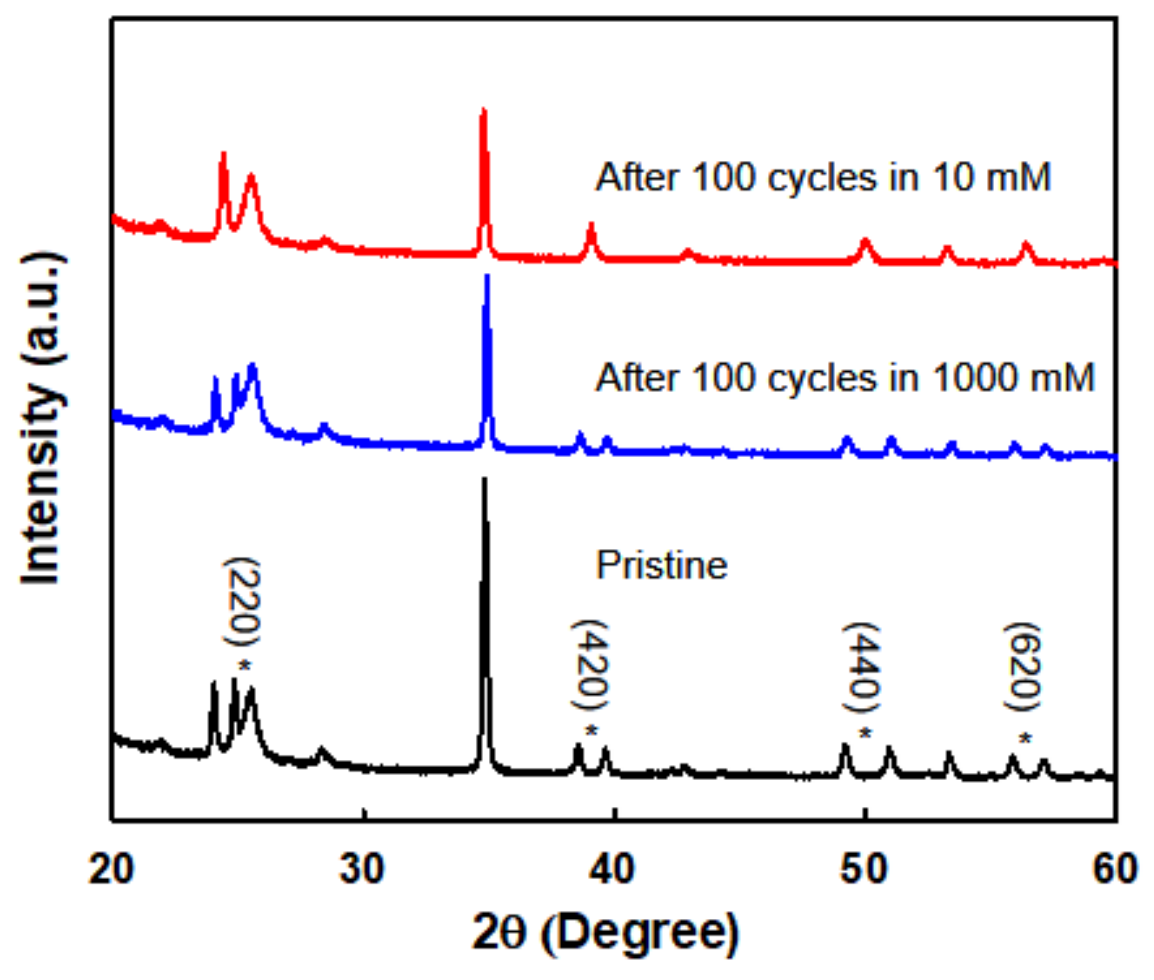

Figure S9 X-ray diffraction (XRD) characterization of nickel hexacyanoferrate (NiHCF) electrode cycled for 100 times in $10 \mathrm{mM}$ (red) and $1000 \mathrm{mM} \mathrm{NaCl}$ (blue) compared to the pristine NiHCF electrode (black). 


\section{References}

1. Guo, J.; Sun, A.; Chen, X.; Wang, C.; Manivannan, A., Cyclability Study of Siliconcarbon Composite Anodes for Lithium-ion Batteries using Electrochemical Impedance Spectroscopy. Electrochim. Acta 2011, 56, 3981-3987.

2. Gaberscek, M.; Moskon, J.; Erjavec, B.; Dominko, R.; Jamnik, J., The Importance of Interphase Contacts in $\mathrm{Li}$ Ion Electrodes: the Meaning of the High-frequency Impedance Arc. Electrochem. Solid-State Lett. 2008, 11, A170-A174. 